\title{
Redução do desprendimento das partículas do solo mediante uso de resíduos vegetais de origem urbana ${ }^{1}$
}

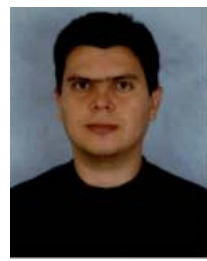

Alexandre M. da Silva² \& Harry E. Schulz ${ }^{3}$

1 Trabalho financiado pela CAPES
${ }^{2}$ Centro de Energia Nuclear na Agricultura (CENA-USP). CEP 13400-970, Piracicaba, SP. E-mail: marcosil@bol.com.br (Foto)
${ }^{3}$ Departamento de Hidráulica e Saneamento (EESC-USP). CEP 13566-590. São Carlos, SP. E-mail: heschulz@sc.usp.br

Protocolo $19-20 / 2 / 2001$

\begin{abstract}
Resumo: O salpicamento, que constitui a primeira etapa do processo da erosão, é provocado pelo impacto das gotas de chuva sobre a superfície desprotegida do solo. Objetivou-se, neste trabalho, avaliar o potencial de redução do salpicamento de partículas de solo através do uso do material originado de restos triturados de poda de jardins e praças públicas ("lixo verde") como cobertura morta sobre a superfície do solo, numa quantidade de cerca de 5,3 t ha-1. Para quantificar o salpicamento, utilizou-se um dispositivo de retenção de partículas salpicadas e comparou-se o peso total dessas partículas contra o dispositivo entre cada condição experimental estudada. Verificou-se redução média de $46,9 \%$ de solo salpicado da condição tratamento sobre a condição controle, permitindo concluir-se que os resíduos originados em áreas urbanas apresentaram boa performance como amenizador da primeira etapa do processo erosivo (salpicamento). Conclui-se, também, que o dispositivo utilizado, embora de confecção simples, permitiu chegar-se a esses resultados e conclusões, de forma clara e objetiva.
\end{abstract}

Palavras-chave: lixo verde, erosão, salpicamento, cobertura morta

\section{Reduction of splash of the soil particles using yard debris}

\begin{abstract}
The splash constitutes the first step of the erosive process and it is started by the impact of raindrop over the uncovered soil surface. The aim of this work was to evaluate the potential of reduction of the splash of the soil particles by using a mulch of the yard debris, equivalent to $5.3 \mathrm{t} \mathrm{ha}^{-1}$. A mean reduction of $46.9 \%$ of splashed soil particles was observed for the treatment in relation to the control condition. The main conclusions are: 1) The yard debris show good performance when used to control splash erosion. 2) The apparatus for the retention of particles is effective and permitted to obtain the above mentioned results.
\end{abstract}

Key words: yard debris, erosion, splash, mulch

\section{INTRODUÇÃO}

A erosão hídrica é um dos mais graves problemas ambientais decorrentes do mau uso do solo, o qual se torna susceptível à erosão hídrica provocada pela água da chuva quando a cobertura vegetal, viva ou morta, é retirada da superfície. Os danos causados pelas gotas de chuva que golpeiam o solo constituem o primeiro passo no processo da erosão, independentemente do grau de inclinação do terreno. As gotas podem ser consideradas bombas em miniatura, que golpeiam a superfície do solo, rompendo os grânulos e torrões, reduzindo-os a partículas menores, lançando-as para longe e, ainda, diminuindo a capacidade de infiltração de água no solo (Bertoni \& Lombardi Neto, 1990).

O processo de salpicamento é sempre citado como parte integrante do processo erosivo, porém muito raramente são encontrados números que demonstram sua influência no processo erosivo de forma geral. Em McIntyre (1958) encontraram-se informações sobre salpicamento e este cita dados em parcelas experimentais (recipientes de grandes proporções) a fim de se analisar o comportamento de salpicamento conforme variação de tipo de solo, declividade e erosividade da chuva.

Paralelamente, um dos mais graves problemas nas áreas urbanas é o acúmulo crescente de resíduos sólidos das mais diversas naturezas. Dentre esses resíduos encontram-se restos de poda de jardins e praças públicas, tão comuns nas áreas urbanas de qualquer município que, em geral, são desprezados, não havendo, normalmente, qualquer forma de aproveitamento do material.

Uma das mais simples e eficaz atividade agrícola que pode ser empregada para se promover a conservação do solo, é a utilização da cobertura morta sobre o mesmo (Bertoni \& Lombardi Neto, 1990; Galeti, 1972). Segundo vários autores, citados por Lombardi Neto et al. (1988), o principal efeito da 
cobertura morta é a absorção da energia cinética da chuva, induzindo a uma redução da desagregação do solo e, conseqüentemente, a uma diminuição da quantidade de solo transportado pela água da chuva. Ettlin \& Stewart (1993) utilizando resíduos de jardins e praças como cobertura morta, obtiveram altas taxas de redução de perdas de solo, mesmo quando colocados em terrenos com alta porcentagem de declividade (42\%), evidenciando o potencial de amenização deste tipo de material no processo erosivo e sua viabilidade de utilização para fins de conservação do solo. Por outro lado, ainda não há informações quantitativas sobre o comportamento deste tipo de material, em especial quanto à capacidade de reduzir a erosão por salpicamento.

Neste sentido, estabeleceu-se, como objetivo do presente trabalho, a avaliação do potencial de amenização do poder erosivo da água da chuva e da desagregação das partículas de solo, utilizando-se como cobertura morta o lixo originado a partir de restos de poda de jardins e praças públicas ("lixo verde").

\section{MATERIAL E MÉTODOS}

Realizou-se o experimento no Centro de Recursos Hídricos e Ecologia Aplicada, pertencente à Escola de Engenharia de São Carlos - USP, localizado no município de Itirapina, SP, entre os meridianos $47^{\circ} 46^{\prime}$ e $47^{\circ} 57^{\prime}$ de longitude Oeste e os paralelos $22^{\circ} 10^{\prime}$ e $22^{\circ} 21^{\prime}$ de latitude Sul (Souza, 1977).

O solo do local é do tipo Latossolo Vermelho-Amarelo Distrófico, textura média. A declividade média da área do experimento é $6,85 \%$ e a cobertura vegetal existente antes da realização do experimento era formada de capim colonião. Esta cobertura foi roçada e o terreno gradeado com grade de disco cerca de 60 dias antes do seu início.

O experimento consistiu na utilização de 6 parcelas de terreno (talhões experimentais) cada uma com 13,20 m de comprimento e 3,30 m de largura, distanciadas cerca de 1,5 m. Em três das seis parcelas não foi colocada qualquer cobertura sobre a superfície, sendo essas parcelas consideradas controles do experimento; nas demais, foram espalhados, uniformemente em cada parcela, cerca de $23 \mathrm{~kg}$ (peso fresco) de material vegetal triturado na forma de cobertura morta, equivalendo a cerca de $5,3 \mathrm{tha}^{-1}$.

Considerou-se início do período experimental o dia em que foi colocada a cobertura sobre o solo, pois as parcelas já estavam devidamente preparadas para tal e também neste mesmo dia foram colocados os dispositivos de coleta de material salpicado.

Quantificou-se a eficiência de proteção do solo, conforme a presença de cobertura morta, utilizando-se um dispositivo de captura de partículas de solo elaborado para este trabalho. Este dispositivo consistiu de um anteparo rígido que foi fixado perpendicularmente ao solo, com $19 \mathrm{~cm}$ de altura e $28 \mathrm{~cm}$ de largura. Sobre a superfície do anteparo foi fixada, com percevejos, uma lâmina retangular de espuma de $1 \mathrm{~cm}$ de espessura, $19 \mathrm{~cm}$ de altura e $28 \mathrm{~cm}$ de largura, com peso previamente conhecido. Sobre o conjunto foi montada uma placa protetora (chapa retangular de $28 \times 6 \mathrm{~cm}$ ) de forma a evitar que a chuva atingisse diretamente a espuma, carreando o material nela salpicado. A Figura 1 (sem escala) mostra, em vista lateral, o "design" do anteparo.

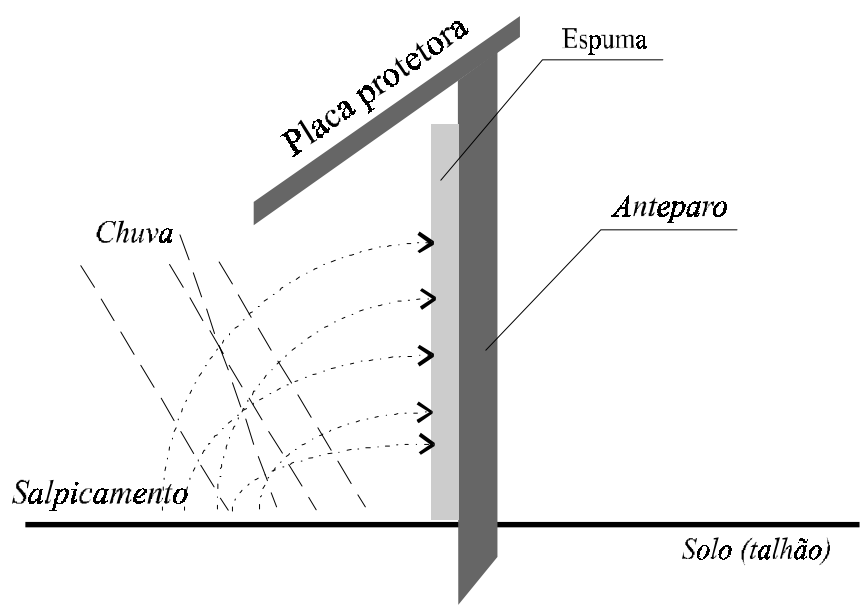

Figura 1. Esquema (vista lateral) ilustrando o design e os componentes do dispositivo desenvolvido para quantificar o salpicamento (dimensões citadas no texto)

Nesta montagem, a espuma fica disposta no sentido vertical e, para cada evento chuvoso, as partículas que se desprendem do solo e atingem a espuma ficam retidas na mesma. A água da chuva que também atinge a espuma, por sua vez, escorre para o solo.

Após cada evento chuvoso, a espuma era destacada do dispositivo, transportada ao laboratório, seca em estufa a $90{ }^{\circ} \mathrm{C}$ por aproximadamente $48 \mathrm{~h}$ e novamente pesada. Do peso seco final foi subtraído o peso da espuma limpa previamente conhecido, obtendo-se a quantidade de solo que foi desprendido e que atingiu a superfície da espuma sendo retido por esta. Foram colocados dois dispositivos de captura de partículas (dispositivos de salpicamento) em cada parcela, de forma paralela, com as espumas ficando em sentidos opostos, visando evitar desvios em função do sentido da chuva. Os experimentos foram realizados entre 15 janeiro e 31 março de 1996.

\section{RESULTADOS E DISCUSSÃO}

A Tabela 1 apresenta os valores de material salpicado, para as parcelas de controle e as parcelas tratadas com cobertura morta. Os valores apresentados são as médias aritméticas entre os seis dispositivos para cada condição experimental em cada evento chuvoso. Esta tabela fornece, também, informações sobre a altura total de chuva precipitada e a erosividade estimada no intervalo entre cada coleta, sendo que esses valores são o somatório de todos os eventos chuvosos ocorridos no intervalo. Os dados de chuva (altura e erosividade) foram extraídos de Silva (1997).

Observa-se acentuada diferença entre os valores médios obtidos para cada data entre as duas condições experimentais. Houve correlação significativa entre a erosividade do período de cada coleta e o valor médio do peso de solo salpicado, para ambas as condições experimentais $\left(\mathrm{R}^{2}=0,85\right.$ - significativo $\alpha=0,01$ ) para a condição controle $\mathrm{e}^{2}=0,90$ (significativo $\alpha=0,01$ ) para a condição tratamento. 
Tabela 1. Quantidade de partículas de solo (g) salpicadas em cada evento chuvoso

\begin{tabular}{|c|c|c|c|c|c|c|}
\hline \multirow{3}{*}{$\begin{array}{c}\text { Data } \\
\text { da Coleta }\end{array}$} & \multirow{3}{*}{$\begin{array}{l}\text { Altura de Chuva } \\
(\mathrm{mm})\end{array}$} & \multirow{3}{*}{$\begin{array}{c}\text { Erosividade } \\
\left(\mathrm{MJ} \mathrm{mm} \mathrm{ha}^{-1} \mathrm{~h}^{-1}\right)\end{array}$} & \multicolumn{4}{|c|}{ Peso Seco das Partículas (g) } \\
\hline & & & \multicolumn{2}{|c|}{ Tratamento } & \multicolumn{2}{|c|}{ Controle } \\
\hline & & & Média & $\mathrm{DP}^{*}$ & Média & $\mathrm{DP}^{*}$ \\
\hline $19 / 01 / 96$ & 31,8 & 126,34 & 15,73 & $\pm 3,921$ & 36,35 & $\pm 3,797$ \\
\hline $22 / 01 / 06$ & 13,5 & 44,14 & 5,50 & $\pm 1,646$ & 11,10 & $\pm 2,762$ \\
\hline $29 / 01 / 96$ & 5,9 & 4,40 & 0,63 & $\pm 0,437$ & 2,62 & $\pm 0,896$ \\
\hline $05 / 02 / 96$ & 44,9 & 565,92 & 20,93 & $\pm 2,558$ & 27,57 & $\pm 5,465$ \\
\hline $12 / 02 / 96$ & 22,1 & 70,46 & 18,65 & $\pm 6,736$ & 24,53 & $\pm 7,006$ \\
\hline $28 / 02 / 96$ & 71,1 & 260,06 & 23,27 & $\pm 6,576$ & 53,00 & $\pm 4,998$ \\
\hline $29 / 02 / 96$ & 15,7 & 71,83 & 8,36 & $\pm 1,211$ & 14,33 & $\pm 3,080$ \\
\hline $11 / 03 / 96$ & 35,5 & 32,24 & 3,57 & $\pm 0,471$ & 9,25 & $\pm 0,612$ \\
\hline $18 / 03 / 96$ & 136,0 & $1.260,98$ & 22,20 & $\pm 2,993$ & 32,58 & $\pm 4,393$ \\
\hline
\end{tabular}

Apesar de não ser possível comparar os dados aqui obtidos com outros autores, devido à provável originalidade da metodologia utilizada e da necessidade de processos comparativos para padronizar resultados, frisa-se que os dados obtidos são bastante úteis para evidenciar dois aspectos importantes na dinâmica chuva-solo: o primeiro aspecto é que este tipo de experimento serviu para fornecer informações quantitativas sobre a primeira etapa do processo de erosão, que é o desprendimento das partículas, processo este sempre descrito, porém não quantificado; o segundo aspecto é que, conforme foi verificado nos dados obtidos, evidencia-se ainda mais a proteção que a cobertura morta confere à superfície do solo pois, em todas as coletas efetuadas, independentemente do volume de chuva, o índice de desprendimento de partículas foi menor nas parcelas onde havia cobertura morta. Neste sentido, observou-se redução média de $46,9 \%$ da condição tratamento sobre a condição controle, calculada a partir do valor médio entre todas as coletas para cada condição experimental, conforme a seguinte expressão:

$$
\text { Redução(\%) }=\left(\frac{\text { controle }- \text { tratamento }}{\text { controle }}\right) 100
$$

Os resultados obtidos provavelmente também sofreram alguma influência do manejo adotado quando da disposição do material sobre o solo, porém, pelo fato de se ter utilizado material triturado disposto uniformemente na superfície do solo, a eficiência de proteção do material vegetal sobre o solo pode ter sido aumentada, considerando-se a proposição de que o melhor manejo de resíduos vegetais, quer seja de origem urbana ou rural, é picar o material e mantê-lo sobre a superfície, não o incorporando ao solo. Desta maneira, obtém-se também aumento da umidade, amenização da temperatura e eliminação ou amenização do déficit de nitrogênio para a cultura que está em desenvolvimento, conforme apontado por Primavesi (1987) e observado neste mesmo trabalho (Silva, 1997). Evidentemente, a essas vantagens se junta a proteção contra o impacto das gotas de chuva, como foi especificamente comprovado neste trabalho.

Os valores da Figura 2, transformados em porcentagem, constituem a diferença de média de peso entre as condições experimentais entre cada data em que ocorreu chuva e proporcionou salpicamento. Como se trata de material orgânico em função do processo de decomposição que o material pode sofrer, este vai sendo mineralizado e incorporado ao solo (este último foi fato visto "in loco" durante o decorrer do experimento). Sendo assim, sugere-se que, com o avanço do tempo, haja decaimento desta eficiência, necessitando-se então de novas aplicações para restituir a cobertura e garantir a conservação do solo continuamente, conforme enfocado por Bertoni \& Lombardi Neto (1990) e Primavesi (1987).

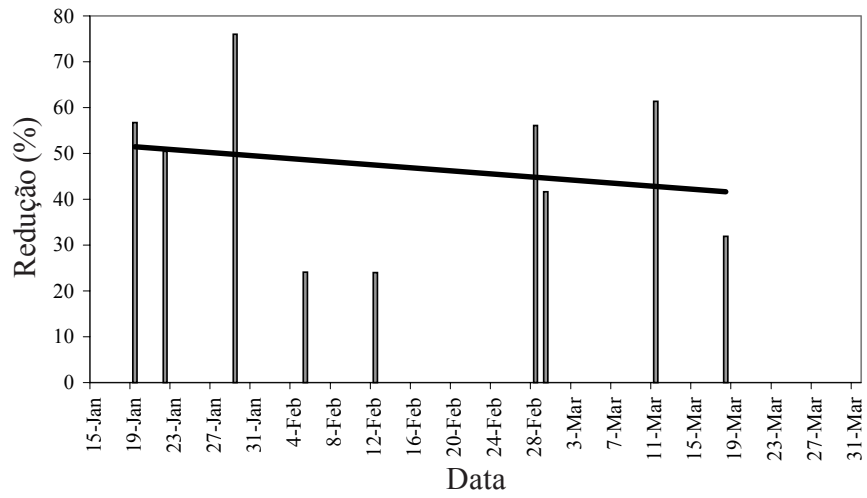

Figura 2. Reta de tendência mostrando decaimento da eficiência da cobertura morta no controle da erosão por salpicamento

Considerou-se boa a performance do dispositivo utilizado para o desenvolvimento do experimento. Contudo, como trata-se de uma primeira versão deste aparato, recomenda-se que ele seja confeccionado e utilizado nos mesmos modos citados no texto em outras localidades e sob diferentes condições de solo, relevo e cobertura do solo, visando uma avaliação do desempenho em situações diferentes daquelas encontradas neste estudo.

\section{CONCLUSÕES}

1. A utilização do lixo verde mostrou-se bastante eficiente e favorável como prática de redução de desprendimento e, conseqüentemente, de perdas de solo por erosão hídrica.

2. Os resultados de salpicamento obtidos com a utilização da metodologia aqui proposta, revelaram informações importantes sobre a primeira etapa do processo erosivo que ocorre no momento em que a gota de água atinge o solo e permitiram, ainda, quantificar esta primeira etapa. 
3. Os resultados são obtidos diretamente em gramas de material salpicado.

\section{AGRADECIMENTOS}

Os autores agradecem ao Centro de Recursos Hídricos e Ecologia Aplicada (CRHEA-EESC-USP) por ceder a área física para realização do experimento, os dados pluviográficos e os laboratórios para realização das análises relativas à pesquisa. Agradecem também à Prefeitura Municipal de São Carlos, SP, por ter cedido o material vegetal já triturado para a realização do experimento.

\section{LITERATURA CITADA}

Bertoni, J.; Lombardi Neto F. Conservação do solo. São Paulo: Ícone, 1990.335 p.

Ettlin, L.; Stewart, B. Yard debris compost for erosion control. Biocycle Journal, Emmaus P.A., n.34, December, p.46-47, 1993.
Galeti, P.A. Conservação do solo: Reflorestamento - clima. Campinas: IMPRES. Instituto Campineiro de Ensino Agrícola, 1972.279p.

Lombardi Neto, F.; De Maria, I.C.; Castro, O.M. de; Dechen, S.C.F., Vieira, S.R. Efeito da quantidade de resíduos culturais de milho nas perdas de solo e água. Revista Brasileira de Ciência do Solo, Campinas, v.12, p.71-75, 1988.

McIntyre, D. S. Soil splash and the formation of surface crusts by raindrop impact. Soil Science. Baltimor, v. 85, p.261-266, 1958.

Primavesi, A.M. Manejo ecológico do solo: A agricultura em regiões tropicais. São Paulo: Nobel. 1987. 549p.

Silva, A.M. Eficácia de resíduos vegetais de podas de praças e ruas usados como cobertura morta no controle da erosão hídrica. São Carlos: USP, 1997. 183p. Dissertação Mestrado

Souza, M. H. A. de O. Alguns aspectos ecológicos da vegetação na região perimetral da represa do Lobo (BrotasItirapina, SP). São Carlos: UFSCar, 1977. 369p. Tese Doutorado 